J. Clin. Chem. Clin. Biochem.

Vol. 26, 1988, pp. 405-414

(C) 1988 Walter de Gruyter \& Co.

Berlin · New York

\title{
Evaluation of a Novel Bayesian Method for Individualizing Theophylline Dosage ${ }^{1}$ )
}

\author{
By U. Stein'2), M. Oellerich
}

Institut für Klinische Chemie, Medizinische Hochschule Hannover, Federal Republic of Germany

G. W. Sybrecht

Abteilung Pneumonologie, Medizinische Universitätsklinik Homburg/Saar, Federal Republic of Germany and

\section{B. Schneider}

Institut für Biometrie, Medizinische Hochschule Hannover, Federal Republic of Germany

(Received September 8, 1987/February 25, 1988)

Summary: A novel Bayesian drug dosing program (Abbott Pharmacokinetic Systems, Theophylline Program) was evaluated. The predictive accuracy of this method was assessed in 10 healthy volunteers receiving single intravenous test doses. Estimates for clearance and distribution volume were compared with those obtained from the area under the curve. The observed prediction error depended largely on sampling time. The deviations were lowest for the distribution volume during the first $60 \mathrm{~min}$ and for clearance at 12 hours after theophylline administration. Furthermore the Bayesian technique was prospectively evaluated in 10 hospitalized and 22 outpatients treated with sustained-release theophylline preparations (Uniphyllin, Bronchoretard, PulmiDur). Predictive precision and accuracy were adequate, if theophylline was given twice daily. The highest predictive accuracy was achieved in outpatients, if predictions were based on trough concentrations. In 19/22 outpatients prediction errors were within a clinically acceptable range (mean prediction error \pm standard deviation; $-0.6 \pm 2.1 \mathrm{mg} / \mathrm{l})$. Moreover in hospitalized patients $(\mathrm{n}=5)$ with twice-daily maintenance regimens, concentration-time curves could mainly be predicted with sufficient accuracy. Hospitalized patients $(n=5)$ with once-daily dosing showed large fluctuations between peak and trough theophylline concentrations in serum. In these patients a reliable prediction of the concentration-time curves was not possible apparently due to non-linearity of theophylline kinetics. Relatively large prediction errors were found in one patient with acute viral respiratory illness and 3 patients with altered absorption. Despite certain limitations the clinical application of the $\vec{B}$ ayesian forecasting method tested appears to be promising.

\section{Introduction}

Theophylline, which is frequently used in the treatment of reversible obstructive airways disease, shows a low toxic/therapeutic ratio. Since there is wide interand intraindividual variability (1) in theophylline

1) Preliminary results of this study were presented at the Symposium Klinisch-Toxikologische Analytik in Salzburg 1987

(Abstract: J. Clin. Chem. Clin. Biochem. 25, 622-623 (1987)).

2) In fulfillment of his thesis (Dr. med.) clearance, attempts to individualize dosage regimens have been made in order to avoid inadequate or toxic serum concentrations of this drug.

The frequency distribution of theophylline values in patients treated in our hospital during the years 1978 to 1986 cleary indicates the difficulty of achieving the optimal dose for this drug (fig. 1). Only about 37 to 54 per cent of the theophylline concentrations determined were within the therapeutic range. The consistently high percentage of theophylline concentra- 


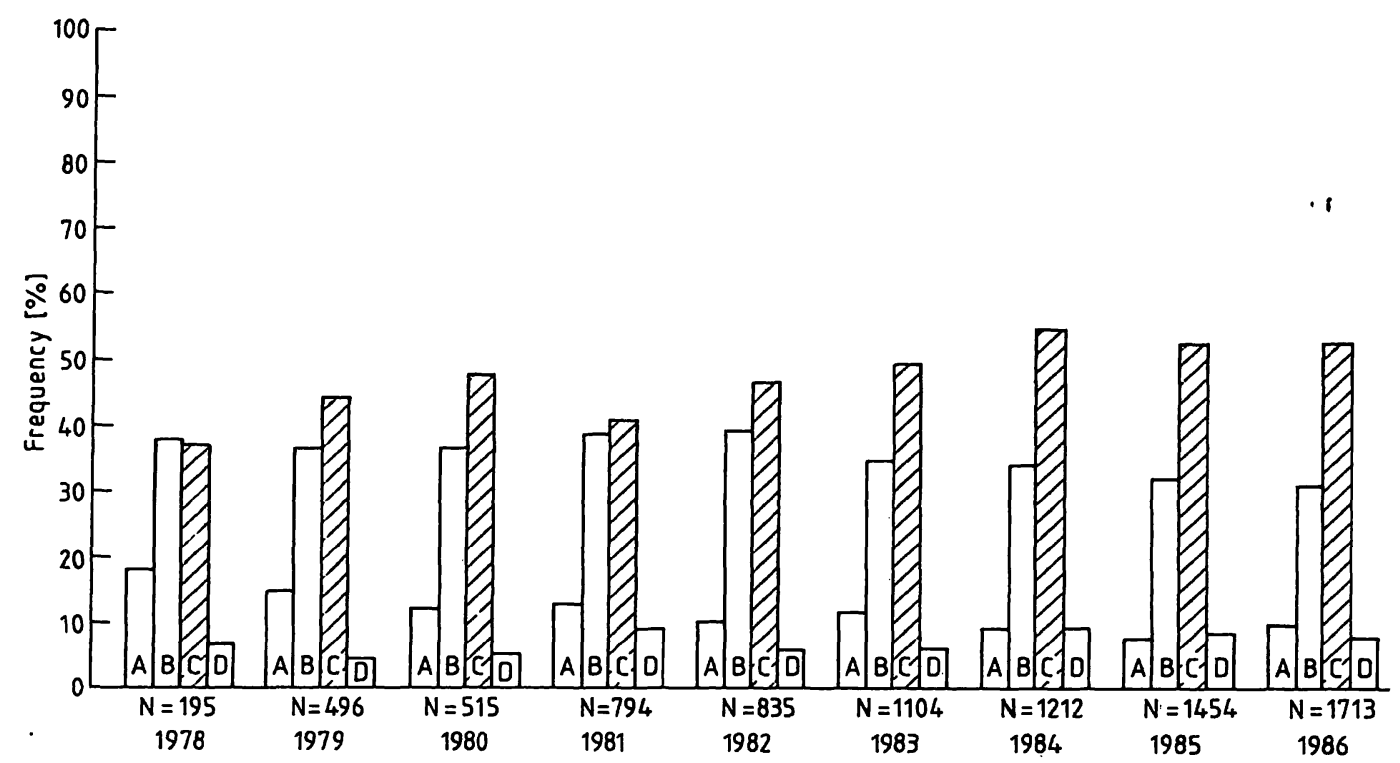

Fig. 1. Frequency distribution of all theophylline concentrations determined in samples from patients with obstructive respiratory disorders treated at our clinic during the years 1978-1986. Concentration ranges:

$\mathrm{A}: \leq 2.5 \mathrm{mg} / \mathrm{l} ; \mathrm{B}: 2.6-7.9 \mathrm{mg} / \mathrm{l} ; \mathrm{C}: 8.0-20.0 \mathrm{mg} / \mathrm{l} ; \mathrm{D}: \geq 20.0 \mathrm{mg} / \mathrm{l}$

tions in the subtherapeutic range is noteworthy. In these patients pharmacokinetic dose prediction methods were not routinely used for individual dosage adjustment.

Usually theophylline serum concentrations from therapeutic drug monitoring are only used in a "trial and error" fashion to optimize the patients dosage regimen. A more rapid and effective way of individualizing theophylline dosage is to use appropiate pharmacokinetic methods for dose prediction $(2-9)$. The Bayesian approach combines a priori information on population distribution of pharmacokinetic parameters with data on one or more actually measured serum theophylline concentrations in estimating the individual patient's clearance and distribution volume $(2,8)$.

This prospective study was designed to evaluate the performance of a novel Bayesian dosage prediction method (Abbott Pharmacokinetic Systems; Theophylline Program) in outpatients and hospitalized patients with obstructive respiratory disease. Moreover, the predictive accuracy of this method for estimating clearance and distribution volume was tested with data from healthy volunteers.

\section{Study Design}

The pharmacokinetics of theophylline were studied in 10 healthy volunteers and in 10 hospitalized and 22 outpatients with obstructive respiratory disease (tab. 1). The healthy test subjects and the patients gave informed consent to voluntary participation in the study.
In normal subjects clearance and distribution volume were estimated with a Bayesian method (Appendix) using theophylline concentrations obtained after a single test dose as described below. In addition, for comparison purposes, clearance and distribution volume were calculated from the area under the curve.

The volunteers (tab. 1) were administered $42.7 \mathrm{ml}$ theophylline ethylenediamine solution ( $=300 \mathrm{mg}$ theophylline, EuphyllinTropflösung Byk Gulden, Konstanz, F. R. G.) by timed constant rate infusion over $20 \mathrm{~min}$. Between $0.25 \mathrm{~h}$ and $12 \mathrm{~h}$ after the end of the infusion, theophylline serum concentrations were determined. For each of the serum concentrations, clearance and distribution volume were predicted by use of the Bayesian method. Moreover, in all subjects, these parameters were estimated from theophylline levels determined at 0.25 and $12 \mathrm{~h}$ after drug administration, as well as from all the measured concentrations. A total of 14 estimates of clearance and distribution volume were obtained for each subject. Prediction error was calculated by subtraction of clearance (distribution volume) determined by the area under curve (AUC) method from the corresponding predicted value (fig. 2,3 ). Percental deviation was calculated as described in the Appendix.

In non-smoking outpatients treated at our hospital blood samples for theophylline determination were drawn at steady-state immediately before and $1 \mathrm{~h}$ after administration of the morning dose. With the Bayesian method individual estimates for clearance and distribution volume were obtained using either the trough or the 1-h-post-dose theophylline concentration. Individual dosage regimens were designed to produce theophylline serum concentrations of 8 to $20 \mathrm{mg} / \mathrm{l}$. Favourable patient responses have been reported for theophylline serum concentration in this range (10). Sustained-release theophylline preparations (Uniphyllin, Mundipharma Limburg, F. R. G.; Bronchoretard, Klinge Pharma, München, F. R. G.; PulmiDur, Astra Chemicals, Wedel/Golstein, F. R. G.; tab. 1) were administered twice-daily. To assess predictive accuracy, steady-state trough theophylline serum concentrations were measured in each patient at 8 a.m., 14 days after dosage adjustment. Predictive aceuracy was assessed by comparing the values of predicted and observed theophylline serum concentrations. Prediction error was calculated by subtraction of measured from predicted serum theophylline concentrations. Based on theoretical con- 
Tab. 1. Patient demographic data.

\begin{tabular}{|c|c|c|c|c|c|c|}
\hline No. & Sex & $\begin{array}{l}\text { Age } \\
\text { (years) }\end{array}$ & $\begin{array}{l}\text { Weight } \\
(\mathrm{kg})\end{array}$ & $\begin{array}{l}\text { Height } \\
(\mathrm{cm})\end{array}$ & $\begin{array}{l}\text { Theophylline dosage/preparation } \\
\text { (mg per day) }\end{array}$ & $\begin{array}{l}\text { Add } \\
\text { med }\end{array}$ \\
\hline \multicolumn{7}{|c|}{ Healthy volunteers } \\
\hline $\begin{array}{c}1 \\
2 \\
3 \\
4 \\
5 \\
6 \\
7^{*} \\
8 \\
9^{*} \\
10\end{array}$ & $\begin{array}{l}q \\
+ \\
q \\
0 \\
9 \\
+ \\
q \\
0 \\
0 \\
9 \\
9 \\
9 \\
9 \\
0\end{array}$ & $\begin{array}{l}27 \\
26 \\
31 \\
53 \\
30 \\
31 \\
31 \\
40 \\
31 \\
27\end{array}$ & $\begin{array}{l}57 \\
58 \\
61 \\
59 \\
75 \\
78 \\
58 \\
63 \\
53 \\
71\end{array}$ & $\begin{array}{l}176 \\
160 \\
180 \\
167 \\
172 \\
190 \\
161 \\
172 \\
175 \\
186\end{array}$ & $\begin{array}{l}- \\
- \\
- \\
- \\
- \\
- \\
- \\
- \\
-\end{array}$ & $\begin{array}{l}- \\
- \\
- \\
- \\
- \\
- \\
- \\
-\end{array}$ \\
\hline
\end{tabular}

Hospitalized patients

\begin{tabular}{|c|c|c|c|c|c|c|}
\hline $\begin{array}{l}\text { R. W. } \\
\text { K. B. } \\
\text { S.H. } \\
\text { Sch. H. } \\
\text { G. G. } \\
\text { K. E.* } \\
\text { S.J. } \\
\text { L. M. } \\
\text { S. G. } \\
\text { F.H. }\end{array}$ & $\begin{array}{l}0 \\
0 \\
0 \\
0 \\
0 \\
0 \\
0 \\
0 \\
+ \\
+ \\
+ \\
0 \\
+ \\
0 \\
0\end{array}$ & $\begin{array}{l}77 \\
44 \\
57 \\
49 \\
60 \\
52 \\
55 \\
58 \\
51 \\
65\end{array}$ & $\begin{array}{l}78 \\
84 \\
66 \\
87 \\
69 \\
60 \\
58 \\
90 \\
60 \\
92\end{array}$ & $\begin{array}{l}176 \\
175 \\
166 \\
180 \\
169 \\
158 \\
156 \\
167 \\
168 \\
185\end{array}$ & $\begin{array}{l}1 \times 900 \text { Uniphyllin } \\
1 \times 900 \text { Uniphyllin } \\
1 \times 600 \text { Uniphyllin } \\
1 \times 900 \text { Uniphyllin } \\
1 \times 800 \text { Uniphyllin } \\
2 \times 400 \text { Uniphyllin } \\
2 \times 400 \text { Uniphyllin } \\
2 \times 400 \text { Uniphyllin } \\
2 \times 400 \text { Uniphyllin } \\
2 \times 600 \text { Uniphyllin }\end{array}$ & $\begin{array}{l}\text { A/Dig/N/D } \\
B / C \\
B / C \\
C / D \\
B / C / D \\
B / C / R \\
B / C \\
B / C \\
B / C / D o x \\
\text { An/B/C/T }\end{array}$ \\
\hline \multicolumn{7}{|c|}{ Outpatients } \\
\hline $\begin{array}{r}1 \\
2 \\
3 \\
4 \\
5 \\
6 \\
7 \\
8 \\
9 \\
10 \\
11 \\
12 \\
13 \\
14 \\
15\end{array}$ & 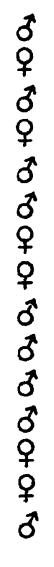 & $\begin{array}{l}54 \\
59 \\
74 \\
38 \\
53 \\
58 \\
24 \\
35 \\
61 \\
57 \\
62 \\
63 \\
28 \\
19 \\
67\end{array}$ & $\begin{array}{l}79 \\
65 \\
75 \\
58 \\
69 \\
95 \\
59 \\
69 \\
81 \\
76 \\
75 \\
75 \\
49 \\
53 \\
91\end{array}$ & $\begin{array}{l}169 \\
162 \\
172 \\
166 \\
179 \\
178 \\
175 \\
165 \\
177 \\
173 \\
178 \\
182 \\
154 \\
168 \\
169\end{array}$ & $\begin{array}{l}2 \times 600 \text { Pulmidur } \\
2 \times 300 \text { Pulmidur } \\
2 \times 400 \text { Uniphyllin } \\
2 \times 500 \text { Bronchoretard } \\
2 \times 500 \text { Bronchoretard } \\
2 \times 450 \text { Pulmidur } \\
2 \times 400 \text { Pulmidur } \\
2 \times 300 \text { Pulmidur } \\
2 \times 500 \text { Bronchoretard } \\
2 \times 450 \text { Pulmidur } \\
2 \times 600 \text { Bronchoretard } \\
2 \times 450 \text { Pulmidur } \\
2 \times 400 \text { Bronchoretard } \\
2 \times 350 \text { Bronchoretard } \\
2 \times 600 \text { Pulmidur }\end{array}$ & $\begin{array}{l}\text { B/C } \\
\text { B/C } \\
\text { An/B/C/N/T } \\
\text { B/C/Dox/tp } \\
\text { B/tp } \\
\text { B/C } \\
\text { B/C/Cr/O } \\
\text { C/T } \\
\text { C/T } \\
\text { B/T } \\
\text { B/C } \\
\text { B/Dig/H } \\
\text { B/C } \\
\text { - } \\
\text { A/B/C/Dig/G/H } \\
\text { Ou/Tr/V }\end{array}$ \\
\hline $\begin{array}{l}16 \\
17 \\
18 \\
19 \\
20\end{array}$ & $\begin{array}{l}0 \\
0 \\
+ \\
0 \\
0 \\
+ \\
0 \\
0\end{array}$ & $\begin{array}{l}68 \\
50 \\
76 \\
64 \\
58\end{array}$ & $\begin{array}{r}93 \\
57 \\
73 \\
67 \\
103\end{array}$ & $\begin{array}{l}180 \\
168 \\
172 \\
165 \\
181\end{array}$ & $\begin{array}{l}2 \times 500 \text { Bronchoretard } \\
2 \times 400 \text { Bronchoretard } \\
2 \times 500 \text { Bronchoretard } \\
2 \times 500 \text { Bronchoretard } \\
2 \times 500 \text { Bronchoretard }\end{array}$ & $\begin{array}{l}\mathrm{B} / \mathrm{C} / \mathrm{T} \\
\mathrm{C} / \mathrm{T} \\
\mathrm{B} / \mathrm{C} \\
\mathrm{B} / \mathrm{C} / \mathrm{T} \\
\mathrm{B} / \mathrm{C}\end{array}$ \\
\hline $\begin{array}{l}21^{1} \\
22^{11}\end{array}$ & $\begin{array}{l}\sigma \\
\delta\end{array}$ & $\begin{array}{l}54 \\
42\end{array}$ & $\begin{array}{l}79 \\
87\end{array}$ & $\begin{array}{l}169 \\
168\end{array}$ & $\begin{array}{l}2 \times 500 \text { Bronchoretard } \\
2 \times 500 \text { Bronchoretard }\end{array}$ & $\begin{array}{l}\mathrm{B} / \mathrm{C} \\
\mathrm{B} / \mathrm{C} / \mathrm{S} / \text { Trim }\end{array}$ \\
\hline
\end{tabular}

(A) - allopurinol, (An) - antihistamine, (B) - B-2-sympathomimetics, (C) - corticosteroids, (Cr) - cromoglycidic acid, (D) - diazepam, (Dig) - digoxin, (Dox) - doxycycline, (G) - glibenclamide, (H) - hydrochlorothiazide, (Ip) - ipratropiumbromide, $(N)$ - nifedipin, $(O)$ - oral contraceptives, $(Q u)$ - quinidine, $(R)$ - ranitidine, $(S)$ - sulphamethoxazole, $(T)$ terbutaline, (Tr) - triamterene, (Trim) - trimethoprim, (V) - verapamil.

$\left.{ }^{*}\right)$ - smokerr, (I) - acute viral respiratory illness, (II) - diarrhoea.

siderations (2) the clinically acceptable range for the absolute prediction error was assumed to be half the width of the therapeutic range.

Hospitalized patients with obstructive respiratory disease were administered theophylline (Uniphyllin, Mundipharma, Limburg, F.R.G.) either as a single evening dose or twice daily (tab. 1). Blood specimens for theophylline determination were drawn during steady-state predose and every $3 \mathrm{~h}$ during a dosage interval of 24 or $12 \mathrm{~h}$. Using the Bayesian method, clearance and distribution volume were estimated in each patient from a theophylline predose concentration. In addition, from the observed concentration-time curves, the peak concentration or all theophylline concentrations except the predose value were used to predict the individual clearance and the distribution volume. For each patient concentration-time curves of theophylline were simulated by use of Bayesian estimates for clearance and distribution volume as described in the Appendix. Predictive accuracy and precision were assessed as described above. 
Procedure for estimation of pharmacokinetic parameters

Pharmacokinetic parameters (clearance and distribution volume) were estimated by use of a novel Bayesian dosage prediction method (Abbott Pharmacokinetic Systems; Theophylline Program; Abbott Diagnostics, Inc., North Chicago, USA) (see Appendix for predictive algorithm). The Bayesian program required input of patient-specific data (age, sex, weight, height, additional medication, smoking habits, concurrent drug therapy, concomitant diseases), the dosing history and available theophylline serum concentrations.

Patient-specific data are used to identify the subpopulation to which the patient belongs. The subpopulation mean estimates of theophylline clearance can be derived from data collected from various patient populations $(1,11)$. Initial subpopulationbased estimates of clearance are generated from an assumed standard clearance of $40 \mathrm{ml} \cdot \mathrm{h}^{-1} \cdot \mathrm{kg}^{-1}$ for nonsmoking healthy adults by multiplication with certain factors accounting for specific patient characteristics (11). The mean population distribution volume estimate is set at $0.51 / \mathrm{kg}$ for all patients (7).

Theophylline serum concentrations resulting from a proposed dosage were simulated with individual estimates for the clearance and the distribution volume, assuming a one compartment open linear model 'with first-order absorption. Individual contributions of each dose were taken into account by use of the principle of linear superposition (12).

For the sustained-release preparations used in our study, the average values for the absorption rate constant and bioavailability are given in table 2 .

Tab. 2. Absorption rate constants and bioavailability of various sustained-release preparations.

\begin{tabular}{llll}
\hline Trade name & $\begin{array}{l}\text { Absorption rate } \\
\text { constant }\left(\mathrm{k}_{\mathrm{a}}\right)\end{array}$ & $\begin{array}{l}\text { Bioavaila- } \\
\text { bility }(\mathrm{F})\end{array}$ & $\begin{array}{l}\text { Refe- } \\
\text { rences }\end{array}$ \\
\hline Uniphyllin & $\mathrm{k}_{\mathrm{a}}=0.150$ & $\mathrm{~F}=0.90$ & $(31)$ \\
Bronchoretard & $\mathrm{k}_{\mathrm{a}}=0.289$ & $\mathrm{~F}=0.88$ & $(32)$ \\
PulmiDur & $\mathrm{k}_{\mathrm{a}}=0.180$ & $\mathrm{~F}=1.00$ & $(33)$ \\
\hline
\end{tabular}

The employed Bayesian forecasting program was written in C. It was run on an IBM personal computer XT ( $512 \mathrm{~kb}$ ram) equipped with an Intel 8087 coprocessor, floppy- and hard disk.

The simulations of concentration-time curves (fig. 6) were run on a Hewlett-Packard $41 \mathrm{CV}$ programmable calculator using equation 9 (Appendix).

\section{Determination of serum theophylline concentrations}

Serum theophylline concentrations were measured by a highly specific fluorescence polarisation immunoassay (Abbott Theophylline II reagent pack, Abbott Laboratories, North Chicago, USA) using the TDx Fluorescence Polarisation Immunoassay (FPIA) System according to the instructions of the manufacturer. The lower limit of the measured range was $0.5 \mathrm{mg} / \mathrm{l}$. With this immunoassay the relative standard deviation between days was $3.6 \%$ over the mid-part of the measuring range $(13,14)$. The performance of the FPIA was constantly checked by internal and external quality control.

\section{Results}

The prediction error observed in healthy subjects for Bayesian estimates of clearance and distribution volume is given in figures 2 and 3 . As expected, the

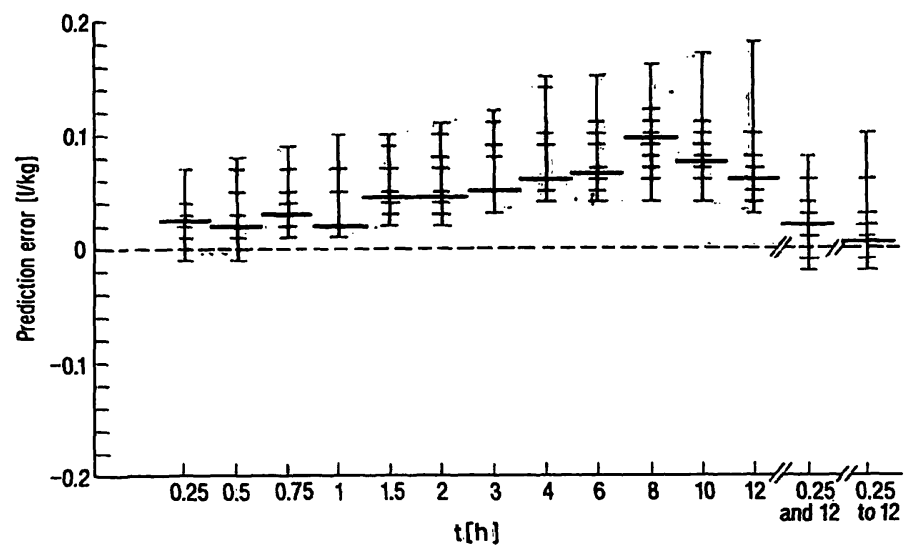

Fig. 2. Prediction error of distribution volume in 10 healthy volunteers after administration of a single theophylline test dose. Each prediction error is represented as a horizontal bar. Columns delimit the range. Median of prediction error is indicated by a horizontal line in each column. Theophylline serum concentrations used for each prediction were determined at different times after the end of the theophylline ethylenediamine infusion as indicated. Moreover, prediction error was calculated from distribution volume estimates based on theophylline levels drawn at 0.25 and $12 \mathrm{~h}$ after drug administration, as well as by use of all concentrations measured between 0.25 and $12 \mathrm{~h}$.

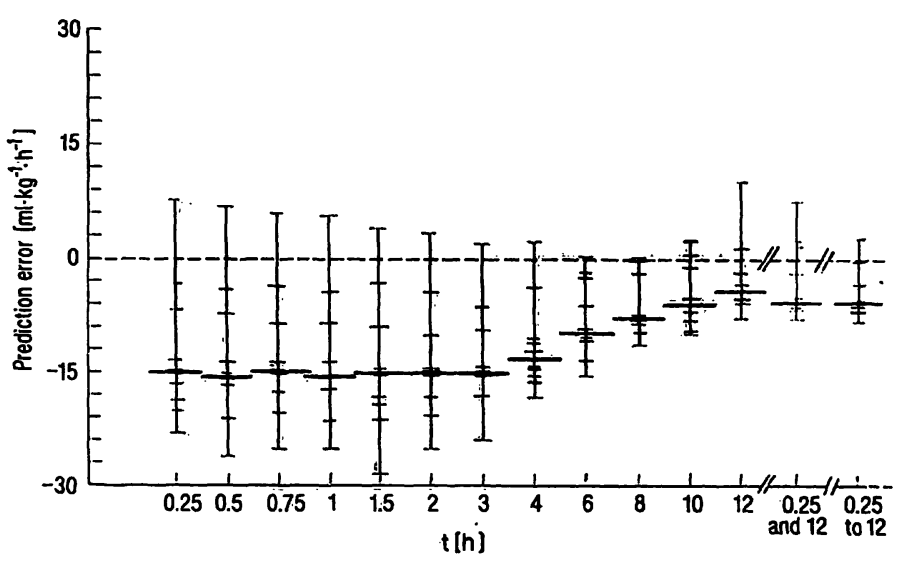

Fig. 3. Prediction or clearance in 10 healthy volunteers after administration of a single theophylline test dose. For further explanation see legend of fig. 2 .

prediction error depended largely on sampling time. It was lowest for the distribution volume during the first $60 \mathrm{~min}$ after intravenous theophylline administration. For clearance, however, the lowest prediction error was observed 12 hours after the end of theophylline infusion. With the Bayesian method, clearance determined from a single theophylline concentration was underestimated on average (median) by 4.2 to $15.7 \mathrm{ml} \cdot \mathrm{kg}^{-1} \cdot \mathrm{h}^{-1}$ (9.7 to $27.8 \%$ ) depending on sampling time. Conversely, distribution volume was overestimated on average (median) by 0.025 to $0.095 \mathrm{l} \cdot \mathrm{kg}^{-1}$ (4.6 to $21.1 \%$ ).

$A^{\circ}$ further improvement of clearance prediction was not achieved, if the prediction was based on the initial and terminal or on all available theophylline concen- 
trations. In contrast, the predictive accuracy of the distribution volume was highest when all available theophylline concentrations were used.

The data show that with only two theophylline concentrations taken at the beginning and at the end of the test period a relatively low prediction error can be achieved for both the clearance and the distribution volume.

Figure 4 shows the steady-state trough theophylline serum concentrations which were achieved in 22 nonsmoking outpatients using the Bayesian method for dose prediction. The twice-daily administered maintenance doses are also shown. Data from one subject with acute viral respiratory illness (tab. 1, No. 21) and a further subject with diarrhoea (tab. 1, No. 22) were excluded from the statistical evaluation. Based on clinical considerations target trough concentrations below the therapeutic range were selected in two patients (tab. 1, No. 8 and No. 17). In these two patients dosage regimens were designed which resulted in theophylline concentrations slightly below the therapeutic range. In one patient (tab. 1, No. 7) an unexpectedly high theophylline serum concentration above the therapeutic range was found which was not accompanied by subjective side effects.

With one exception these outpatients showed comparable predicted and observed serum theophylline concentrations. Predictions were either based on a theophylline level determined 1-h-post-dose (column A, fig. 4) or on a trough value (column B, fig. 4). The mean absolute deviations between predicted and observed concentrations were $14.9 \%$ (range: $0.0-$ $28.9 \%$ ) and $12.5 \%$ (range: $1.3-28.8 \%$ ) with predictions based on 1-h-post-dose and on trough values respectively. If predictions were based on the trough value (column $B$ ), there was no significant difference between the mean value of predicted and measured theophylline concentration ( $p>0.05$, paired t-test). With the 1-h-post-dose value, however, the mean value (column $\mathrm{A}$ ) was significant lower than that of the measured theophylline concentration $(p<0.02$, paired t-test).

Figure 5 shows the prediction error observed by use of the Bayesian method with 1-h-post-dose value (shaded column) and trough concentration (clear column). The mean prediction error is indicated by the horizontal line in the centre of each column. Vertical columns represent one standard deviation on either side of the mean prediction error. If predictions are to be clinically acceptable, $68 \%$ of prediction errors should fall within the range delimited by broken lines. The data from our study indicate that in non-smoking outpatients the predictive accuracy and precision is
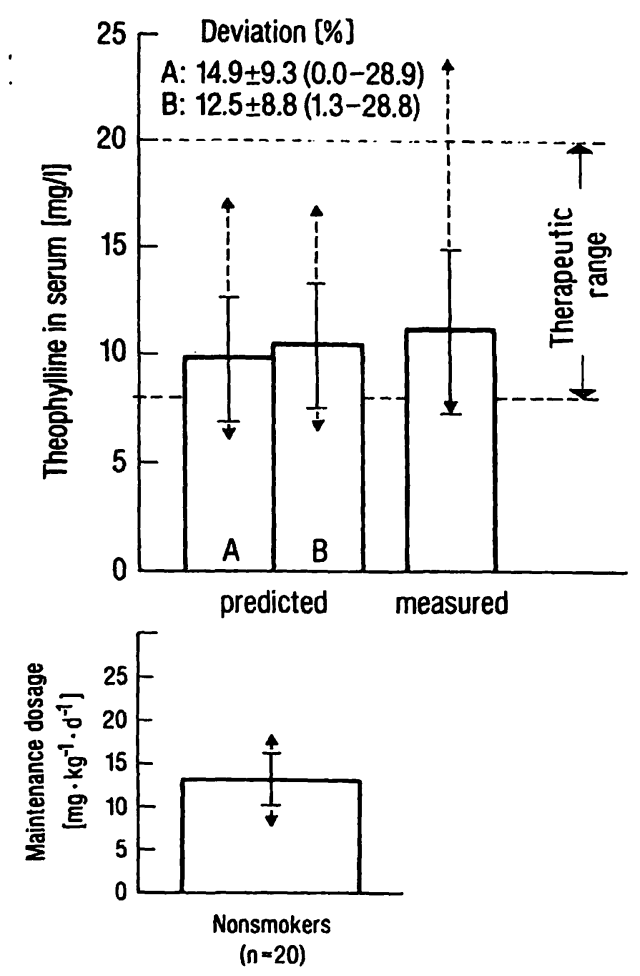

Fig. 4. Comparison between predicted and measured trough steady-state theophylline serum concentrations in 20 non-smoking outpatients. Column A represents theophylline trough concentrations predicted from 1-h-postdose values and column $B$ those predicted from trough concentrations. The daily administered theophylline maintenance dose is also given. The columns show the mean values with standard deviation (vertical bars) and range (triangles). Mean deviation (\%) between predicted and observed concentration was calculated as described in the Appendix.

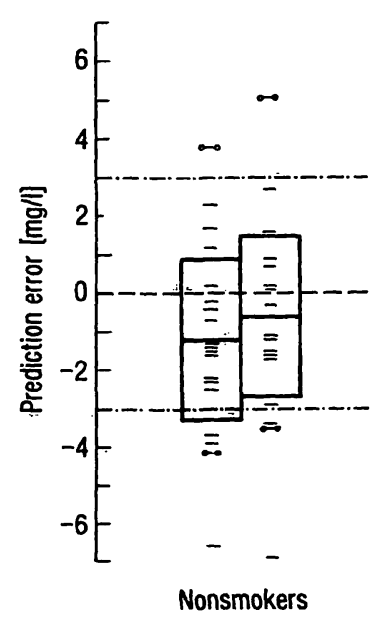

Fig. 5. Prediction errors (predicted minus measured values) for trough steady-state serum theophylline concentrations observed in 22 non-smoking outpatients. Predictions were performed by use of 1 -h-post-dose value (shaded column) and the trough value respectively (clear column). The columns delimit one standard deviation on either side of the mean prediction error indicated by the horizontal line in each column. The horizontal bars represent the observed individual prediction errors. The broken lines (- ) delimit the clinically acceptable range for one standard deviation of the prediction error. Two patients were excluded from the statistical evaluation:

- patient with acute viral respiratory illness, - 0 patient with diarrhoea. 
clinically acceptable. Mean values of predicted theophylline serum concentrations were slightly lower than averaged observed concentrations (fig. 4). The corresponding mean prediction errors were $-1.2 \mathrm{mg} / 1$ and $-0.6 \mathrm{mg} / \mathrm{l}$ for predictions based on the 1-h-postdose and the trough values, respectively (fig. 5).

As expected, relatively large prediction errors were observed for the two patients excluded from the study because of diarrhoea and viral infection (fig. 5). The patient who developed an unexpectedly high theophylline concentration also showed a large prediction error of $-6.6 \mathrm{mg} / \mathrm{l}$ and $-6.9 \mathrm{mg} / \mathrm{l}$, respectively (fig. 5).

In hospitalized patients, the observed and predicted concentration-time curves of steady-state theophylline serum concentrations were compared (fig. 6). In patients who received a sustained-release theophylline preparation (Uniphyllin) twice-daily, all but one of the observed theophylline concentrations were in good agreement. Prediction error ranged from 2.4 $\mathrm{mg} / \mathrm{l}$ to $-2.4 \mathrm{mg} / \mathrm{l}$. In patient S. C., who showed a noticeable lag-phase, prediction errors between 4.6 $\mathrm{mg} / \mathrm{l}$ and $-2.0 \mathrm{mg} / \mathrm{l}$ were found.

If, however, theophylline was given as a single evening dose, a reliable prediction of the subsequent concentration-time curve was not possible. Predictions from trough concentrations resulted in a substantial underestimation of peak concentrations. Prediction errors ranged from $4.8 \mathrm{mg} / \mathrm{l}$ to $-5.8 \mathrm{mg} / \mathrm{l}$ in patients without lag-phase. In these cases prediction error tended to decrease during the second half of the dosage interval. In addition, predictive accuracy was tested, using theophylline concentrations of the represented concentration-time curves. If the prediction of the concentration-time curves was based on the observed theophylline peak concentrations, the prediction error was relatively low for peak concentrations (range: $-0.2 \mathrm{mg} / \mathrm{l}$ to $-2.1 \mathrm{mg} / \mathrm{l}$ ) and comparatively high for trough concentrations (range: $7.3 \mathrm{mg} / 1$ to $1.6 \mathrm{mg} / \mathrm{l}$ ). Even if all theophylline concentrations observed after dosage administration were used, predicted and observed concentration-time curves were largely discrepant. In one patient (Sch.H.) an extensive lag-phase occurred, rendering a dosage prediction impossible.

In table 3 Bayesian estimates for clearance and distribution volume are shown. In each hospitalized patient receiving theophylline twice-daily, estimates for these parameters were in good agreement irrespective of whether trough, peak or all theophylline concentrations after dose administration were used for prediction. In patients treated with high single evening doses, clearance estimates from trough concentrations were significantly higher than those resulting from
Tab. 3. Bayesian estimates for clearance and distribution volume obtained in hospitalized patients treated with a sustained-release theophylline preparation (Uniphyllin).

\begin{tabular}{llll}
\hline Patient & $\begin{array}{l}\text { Clearance } \\
\left(\mathrm{ml} \cdot \mathrm{kg}^{-1} \cdot \mathrm{h}^{-1}\right)\end{array}$ & & $\begin{array}{l}\text { Distribution } \\
\text { volume }\left(\mathrm{l} \cdot \mathrm{kg}^{-1}\right)\end{array}$ \\
\cline { 2 - 3 } & $\mathrm{t}^{\mathrm{a}} \mathrm{p}^{\mathrm{b}} \mathrm{a}^{\mathrm{c}}$ & $\mathrm{t}^{\mathrm{a}} \mathrm{p}^{\mathrm{b}} \mathrm{a}^{\mathrm{c}}$ \\
\hline
\end{tabular}

Twice daily dosage

\begin{tabular}{|c|c|c|c|c|c|c|c|c|}
\hline $\begin{array}{l}\text { K. E. } \\
\text { S. J. } \\
\text { L. M. } \\
\text { S. C. } \\
\text { F. H. }\end{array}$ & & $\begin{array}{l}49.08 \\
55.96 \\
53.05 \\
55.27 \\
27.84\end{array}$ & $\begin{array}{l}42.76 \\
49.51 \\
47.65 \\
49.65 \\
28.11\end{array}$ & $\begin{array}{l}45.39 \\
53.90 \\
55.97 \\
54.16 \\
27.45\end{array}$ & & $\begin{array}{l}0.54 \\
0.54 \\
0.64 \\
0.50 \\
0.54\end{array}$ & $\begin{array}{l}0.53 \\
0.54 \\
0.62 \\
0.51 \\
0.54\end{array}$ & $\begin{array}{l}0.47 \\
0.52 \\
0.59\end{array}$ \\
\hline & $\overline{\mathbf{x}}:$ & 46,48 & 42.01 & 45.68 & $\overline{\mathbf{x}}:$ & 0.57 & 0.56 & . \\
\hline
\end{tabular}

Single evening dosage

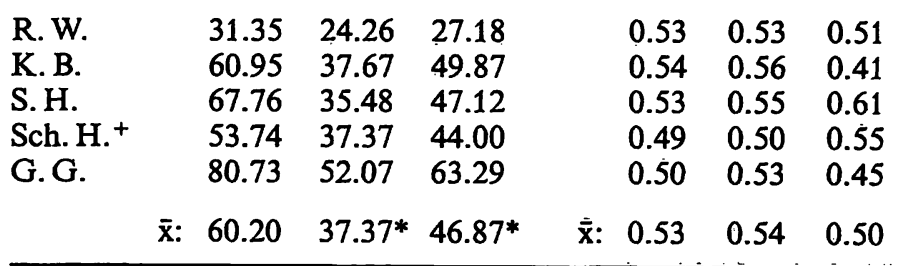

$\left(^{*}\right)$ - Differs significantly from the corresponding prediction based on the trough value $(p<0.05$ paired $t$-test)

$\left(t^{2}\right)$ - Estimation from trough value

$\left(p^{b}\right)$ - Estimation from peak value

$\left(a^{c}\right)$ - Estimation from all observed values after dosage administration

$\left(^{+}\right)$- Patients with lag-phase; values excluded from statistical evaluation

peak concentrations. Bayesian estimates for distribution volume obtained by using the trough, the peak or all the theophylline concentrations showed no significant differences.

\section{Discussion}

In recent years the use of individualized dosage regimens has gained increasing importance in the long term treatment of asthma with theophylline. The pharmacokinetic variability observed with theophylline makes individual dosage adjustment difficult. Therefore the monitoring of theophylline serum concentrations has become current practice. In addition various methods have been proposed for dosage prediction $(2-9,15,16)$. Single point methods $(6,9,15$, 16) which may be used without a computer have the disadvantage that they can only be used at the very beginning of the treatment.

Our study shows, that the Bayesian approach is more flexible, as it allows dosage predictions at any time during theophylline therapy. However, data from our single dose study (figs. 2 and 3) and from ambulatory patients with twice-daily maintenance regimens (figs. 4 and 5) demonstrate that the predictive accuracy 

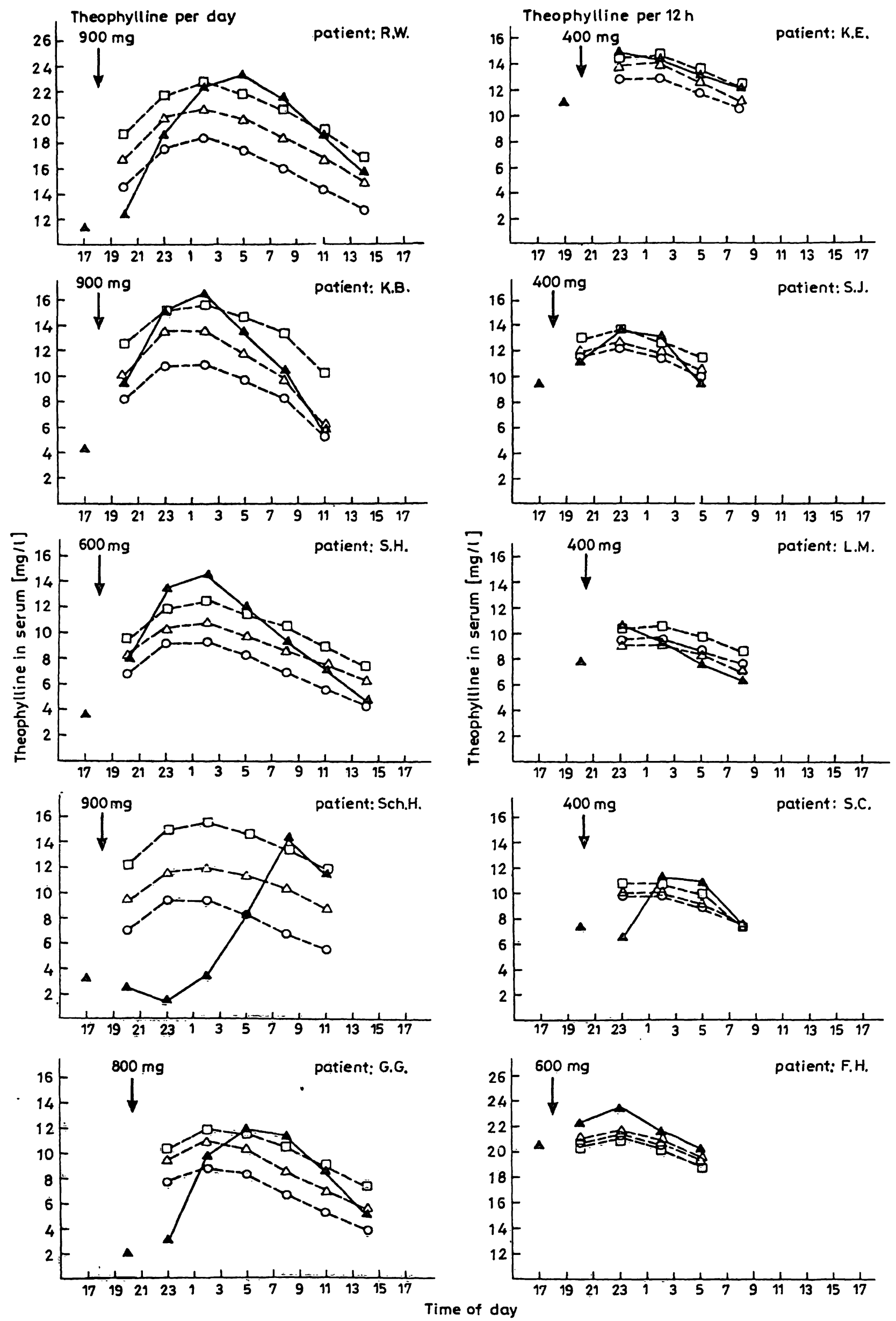

Fig. 6. Comparison between predicted ( $0-0$ from predose value, $\square-\square$ from peak value, $\Delta-\Delta$ by use of all values with exception of the predose value) and measured $(\boldsymbol{\Delta}-\boldsymbol{\Delta})$ steady-state serum theophylline concentrations in hospitalized patients with obstructive lung disease. 
depends on the time of blood sampling. Serum concentrations taken during the initial distribution period yielded a lower prediction error for distribution volume, whereas concentrations taken during the terminal elimination period resulted in a lower prediction error for clearance (figs. 2 and 3 ).

An appropiate sampling time must be clinically practicable and ensure a sufficient predictive accuracy. Therefore, outpatients were investigated to ascertain whether the trough or the 1-h-post-dose theophylline concentration would be more convenient. It was found that with the trough theophylline serum concentration a significantly higher predictive accuracy could be obtained than with the 1-h-post-dose value (fig. 4 and 5). It appeared not to be reasonable to use both values, since due to the time-dependent weighting of measured theophylline concentrations the Bayesian pharmacokinetic parameter estimates are primarily based on the most recently determined values (8). It is to be expected that an increased predictive accuracy can be achieved, if a trough concentration in combination with the preceding 1-h-post-dose value of the same dosage interval is used. In outpatients, however, this would not be practical, since the patients would have to return to the clinic.

The results of our study demonstrate that the Bayesian forecasting method permits the prediction of theophylline serum concentrations in outpatients with a clinically acceptable prediction error. This applies, however, only to twice-daily dosage regimens with the sustained-release theophylline preparations used in our study.

Relatively large prediction errors were observed in 3 outpatients, presumbably due to changes in clearance (tab. 1, No. 21), altered absorption (tab. 1, No. 22) and non-linear kinetics (tab. 1, No. 7).

In hospitalized patients with twice-daily maintenance regimens, the concentration-time curves of theophylline could generally be predicted with sufficient accuracy. Patients with once-daily dosing, however, showed much larger fluctuations between peak and trough theophylline concentrations in serum than those treated with twice-daily doses (fig. 6). In this group of patients, clearance estimates from trough theophylline concentrations were significantly higher than those obtained with peak concentrations (tab. 3). This finding points to a non-linearity of theophylline kinetics in these patients. Also other investigators $(17-21)$ have observed that the pharmacokinetics of theophylline may be non-linear in certain individuals.

Considering the relatively high evening doses it may be speculated that a saturation of theophylline kinet- ics occurred. Since dosage regimens with high single daily doses are increasingly used in patients with nocturnal asthma $(22,23)$, problems due to dosedependent theophylline kinetics will be encountered more often in clinical practice. 'Therefore caution should be exercised when using drug dosing programs based on linear kinetics for individualization of theophylline therapy.

In a different recent study dealing with once daily dosing, Chrystyn et al. (34) reported on some loss of precision in the prediction of peak theophylline concentrations using Bayesian estimates derived from the $24 \mathrm{~h}$ post-dose values. For practical purposes sampling times between 12 and $18 \mathrm{~h}$ post dose were suggested by these authors for patients receiving theophylline once daily.

Further problems arise from altered absorption. In two of the 10 hospitalized patients (tab. 1 and fig. 6: S.C. and Sch.H.) a lag-phase was observed, which, in one of these cases (Sch.H.), rendered an appropriate dosage prediction impossible.

In order to avoid problems arising from dose-dependent theophylline kinetics, Bayesian methods involving Michaelis-Menten kinetics should be developed. Such procedures have already been described for phenytoin (24-26).

Furthermore, from theoretical considerations the Bayesian method as used in our study has certain disadvantages. The posterior distribution does not belong to the same class as the prior distribution (i.e. normal distribution). The mode of the distribution can be calculated only approximately with iterative procedures $(27,28)$ and does not coincide with the mean or median of the distribution. If serum theophylline concentration measurements of an individual patient are used in the posterior distribution, the mode can be considered as the best "estimate" of this individual patient's pharmacokinetic parameters from prior population-specific information and actual drug level measurements. Both disadvantages result from the fact that the pharmacokinetic function is nonlinear in the parameters. An alternative Bayesian approach, which may avoid these problems, has recently been suggested (8).

The practicability of the Bayesian method tested is acceptable. The time needed to perform a dosage prediction is about 10 to 15 minutes, provided that all necessary data are available.

In conclusion, the clinical application of the tested Bayesian forecasting method appearrs to be promising. The user of this program, however, must be aware of the discussed limitations. 


\section{Appendix}

In the employed drug dosing program an algorithm is used, which represents an application of the Bayes formula (29) to pharmacokinetic parameter estimation. This formula uses as "mediator" between the $a$ priori and a posteriori distribution, the likelihood. If we denote the prior distribution (density) of the parameter $p$ with $q(p)$, the likelihood (density) of the measurement $c$ for a given parameter value $p$ with $\mathrm{f}(\mathrm{c} / \mathrm{p})$ and the posterior distribution (density) with $\mathrm{g}(\mathrm{p} / \mathrm{c})$, Bayes formula reads:

$g(p / c)=\frac{f(c / p) \cdot q(p)}{h(c)}$

The denominator $\mathrm{h}(\mathrm{c})$ is the "unconditional" distribution (density) of $c$ and is calculated as:

$h(c)=\int f(c / p) q(p) d p$,

where integration is done over the range of $p$.

The application of this approach to pharmacokinetic parameter estimation is straightforeward:

Suppose that in a pharmacokinetic study with an individual (e.g. patient or volunteer) at times $t_{1}, \ldots t_{m}$ serum concentrations $c_{1}, \ldots c_{\mathrm{m}}$ of some compound are measured and these measurements $c_{\mathrm{i}}$ can be additively decomposed in a functional term $c^{*}\left(\mathrm{t}_{\mathrm{i}} ; \mathrm{p}_{1}, \ldots \mathrm{p}_{\mathrm{n}}\right)(\mathrm{de}-$ pending on $n$ individual kinetic parameters $\left.p_{1}, \ldots p_{n}\right)$ and an error term $\mathbf{e}_{\mathbf{i}}$ (residual plasma concentrationerror):

$c_{\mathrm{i}}=c^{*}\left(\mathrm{t}_{\mathrm{i}} ; \mathrm{p}_{1}, \ldots \mathrm{p}_{\mathrm{n}}\right)+\mathrm{e}_{\mathrm{i}}$

The functional term may be a feasible expression for the time-course of the serum concentrations; e.g. the open one-compartment function:

$c^{*}\left(\mathrm{t} ; \mathrm{p}_{1}, \mathrm{p}_{2}\right)=\mathrm{p}_{1} \mathrm{e}^{-\mathrm{p}_{2} t}$

for a bolus injection or the Bateman function:

$c^{*}\left(\mathrm{t} ; \mathrm{p}_{1}, \mathrm{p}_{2}, \mathrm{p}_{3}\right)=\mathrm{p}_{1}\left(\mathrm{e}^{-\mathrm{p}_{2} t}-\mathrm{e}^{-\mathrm{p}_{3} t}\right)$

for oral application, where $\mathrm{p}_{1}$ is a function of the dose, bioavailability and distribution volume, $\mathrm{p}_{2}$ the elimination constant (clearance divided by volume of distribution) and $\mathrm{p}_{3}$ the apparent first order absorption rate.

Usually it is assumed that the $\mathrm{e}_{\mathrm{i}}$ are realisations of independent, normally distributed random variables with mean 0 and variance $\sigma_{\mathrm{e}}^{2}$. With this assumption the $c_{i}$ are - for fixed parameter values $p_{1}, \ldots p_{n}-$ realisations of independent, normally distributed random variables with mean $c^{*}\left(t_{i} ; p_{1}, \ldots p_{n}\right)$ and variance $\sigma_{e}^{2}$; so the likelihood is: $\frac{1}{(2 \pi)^{\frac{m}{2}}} e^{-\frac{1}{2 \sigma_{\sigma}^{2} \Sigma\left(q-c^{*}\left(t_{1} ; p_{1}, \ldots p_{n}\right)\right)^{2}}}$

$(2 \pi)^{\frac{m}{2}}$

For prediction purposes one can assume that the parameters as well as the residual variance depend on further parameters or patient characteristics like sex, age or state of illness; but for the moment we neglect these dependencies.

It seems reasonable to assume as prior distribution of the parameters $p_{j}$ a multivariate normal distribution with some assumed mean vector:

$\mathrm{p}^{* \prime}:=\left(\mathrm{p}_{i}^{*}, \ldots \mathrm{p}_{\mathrm{n}}^{*}\right)$

and covariance matrix $s_{p}$. If, in a first attempt, the parameters are assumed as independent (which is not a feasible assumption) the covariance matrix reduces to a diagonal matrix with the variances $\sigma_{\mathrm{p}_{\mathrm{j}}}^{2}$ as diagonal elements, and the $a$ priori distribution is simply:

$\frac{1}{(2 \pi)^{\frac{n}{2}}} e^{-\frac{1}{2} \Sigma \frac{\left(p_{j}-p_{j}^{0}\right)^{2}}{\sigma_{p j}^{2}}}$

Both assumptions lead - according to Bayes formula - to the a posteriori distribution density whose logarithm is proportional to:

$\sum_{j=1}^{n} \frac{\left(p_{j}-p_{j}^{*}\right)^{2}}{\sigma_{p_{j}}^{2}}+\sum_{i=1}^{m} \frac{\left(c_{i}-c^{*}\left(t_{i} ; p_{1}, \ldots p_{n}\right)\right)^{2}}{\sigma_{c}^{2}}$

It should be remarked that this a posteriori distribution is not a normal distribution and the parameters $\mathrm{p}_{\mathrm{j}}$ are $a$ posteriori dependent, in spite of the $a$ priori independence assumption.

The detailed derivation of this algorithm and its application in the drug dosing program has recently been described (8).

For the simulation of concentration time profiles (fig. 6) the following equation was used:

$c_{\infty}=$
$\frac{k_{a} F D_{m}}{V_{d}\left(k_{a}-K_{e}\right)}\left[\left(\frac{1}{1-e^{-K_{c} \tau}}\right) e^{-K_{c} l}-\left(\frac{1}{1-e^{-k_{a} \tau}}\right) e^{-k_{a} l}\right]$

where $c_{\infty}$ denotes the serum steady-state drug concentration at time $t$ during a dosing interval $\tau, F$ is the fraction of the administered dose $D_{m}$, which is absorbed, $V_{d}$ is the distribution volume, while $K_{c}$ and $\mathrm{k}_{\mathrm{a}}$ are the elimination rate constant and the absorption rate constant, respectively.

For calculation of the theophylline clearance $\left(l \cdot h^{-1}\right)$ and distribution volume (l) of the hospitalized patients the lean body weight (30) was used. 
Mean (median) \% deviation was calculated from the absolute values of percental deviation (D) observed in each individual:

\section{References}

1. Juskow, W. J., Gardener, M. J., Mangione, A., Schentag, J. J., Koup, J. \& Vance, J. W. (1979) J. Pharm. Sci. 68, $1358-1366$.

2. Sheiner, L. B., Beal, S., Rosenberg, B. \& Marathe, V. V. (1979) Clin. Pharmacol. Ther. 26, 294-305.

3. Klotz, U. (1983) J. Clin. Chem. Clin. Biochem. 21, 649658.

4. Hurley, S. F., Dziukas, L. J., McNeil, J. J. \& Brignell, M. J. (1986) Am. Rev. Respir. Dis. 134, 1219-1224.

5. Gilman, T. M., Muir, K. T., Jung, R. C. \& Walberg, C. B. (1984) J. Pharm. Sci. 74, 508-514.

6. Slattery, J. T., Gibaldi, M. \& Koup, J. R. (1980) Clin. Pharmacokinet. 5, 377-385.

7. Peck, C. C. (1984) In: Pharmacokinetic Basis for Drug Treatment (Benet, L. Z., Massoud, N. \& Gambertoglio, J. G., eds.) Raven Press, New York, pp. 349-356.

8. Oellerich, Mi \&\& Schneider, B. In: Clinical Biochemistry (Curtius, H. G. \& Roth, M., eds.) Volume: Data Presentation and Interpretation (Keller, H. \& Trendelenburg, Chr., eds.) W. de Gruyter \& Co., Berlin, in press.

9. Goldstein, R. S., Allen, L. C., Thiessen, J. J., Michalko, K., Dyneka, N. \& Woolf, C. R. (1986) Chest 89, 103-108.

10. Jenne, J. W., Wyze, E., Rood, F. S. \& McDonald, F. M. (1972) Clin. Pharmacol. Ther. 13, 349-360.

11. Powell, J, R., Vozeh, S., Hopewell, P., Costello, J., Sheiner, L. B. \& Riegelman, S. (1978) Am. Rev. Respir. Dis. 118, 229-238.

12. Gibaldi, M. \& Perrier, D. (1982) Pharmacokinetics, 2nd ed., Marcel Dekker, New York.

13. Niemann, A., Oellerich, M., Schumann, G. \& Sybrecht, G. W. (1985) J. Clin. Chem. Clin. Biochem. 23, 725-732.

14. Oellerich, M., Külpmann, W. R., Beneking, M., Haindl, H. \& Mueller-Vahl, H. (1983) In: Biologie Prospective-5e Colloque International de Pont-a-Mousson - Masson ed., pp. 1169-1173.

15. Oellerich, M., Ranke, C., Schmidt, G. \& Sybrecht, G. W. (1983) Brit. J. Clin. Pract., Suppl. 23, 37-41.

16. Wilkens, J. H., Neuenkirchen, H., Sybrecht, G. W. \& Oellerich, M. (1984) Eur. J. Clin. Pharmacol. 26, 491-498.
$\mathrm{D}=\frac{\mathrm{p}-\mathrm{m}}{\mathrm{m}} \cdot 100$

(Eq. 10)

where $\mathrm{p}$ is the predicted value and $\mathrm{m}$ the measured value.

17. Lesko, L. J. (1986) J. Allergy Clin. Immunol. 78, 723727.

18. Ishizaki, T. \& Kubo, M. (1987) Ther. Drug Monit. 9, $11-20$.

19. Butcher, M. A., Fražer, L. A., Reddel, H. K. \& Marlin, G. E. (1982) Br. J. Clin. Pharmacol. 13, $241-243$.

20. Pancorbo, S., Benson, J., Goetz, D., Moore, K., Vaida, A \& Johnson, D. (1983) Ther. Drug Monit. 5, 173-177.

21. Dahlqvist, R., Billing, B., Miners, J. O. \& Birkett, D. J. (1984) Ther. Drug Monit. 6, 290-297.

22. Neuenkirchen, H., Wilkens, J. H., Oellerich, M. \& Sybrecht, G. W. (1985) Eur. J. Respir. Dis. 66, 196-204.

23. Arkinstall, W. W., Atkins, M. E., Harrison, D. \& Stewart, J. H. (1987) Am. Rev. Respir. Dis. 135, 316-321.

24. Vozeh, S., Muir, K. T., Sheiner, L. B. \& Follath, F. (1981) J. Pharmacokinet. Biopharm. 9, 130-146.

25. Martin, E., Tozer, T. N., Sheiner, L. B. \& Riegelman, S. (1977) J. Pharmacokinet. Biopharm. 5, 579-596.

26. Mullen, P. \& Foster, R. (1979) J. Pharm. Pharmacol. 31 $100-104$

27. Horowitz, D. L. \& Homer, L. D. (1970) Analysis of biomedical data by time-sharing computers. 1 . Non-linear regression analysis. Project No. MR 005: 20-0287, Report No. 25, Naval Medical Research Institute, National Naval Medical Center, Bethesda, Md. 20014.

28. Peck, C. C. \& Barrett, B. B. (1979) J. Pharmacokinet. Biopharm. 7, 537-541.

29. Bayes, Th. (1763) Philos. Trans. R. Soc. London 53, 370418.

30. Wissenschaftliche Tabellen Geigy, Teilband Somatometrie und Biochemie (1982) 8th ed., Ciba-Geigy, Basel, pp. 9-12.

31. Oellerich, M. \& Sybrecht, G. W., unpublished results.

32. Schneider, G. F., Heese, G. U., Huber, H. J., Janzen, N., Juenger, H., Moser, C. H. \& Stanislaus, F. (1981) Arzneim. Forsch./Drug Res. 31, 1489-1497.

33. Wemhöner, S., Oellerich, M. \& Sybrecht, G. W. (1981) Prax. Pneumol. 35, 36-41.

34. Chrystyn, H., Mulley, B. A. \& Peake, M. D. (1987) Br. J. Clin. Pharmac. 24, 301-307.

Prof. Dr. M. Oellerich

Institut für Klinische Chemie

Medizinische Hochschule Hannover

Konstanty-Gutschow-Str. 8

D-3000 Hannover 61 